\title{
William Potts Dewees (1768-1841) of Pennsylvania: pioneer of perinatal medicine in America
}

\author{
Peter M Dunn
}

William Potts Dewees was born in Pottsgrove, Pennsylvania, in 1768. His father, who died while he was young, was of Swedish descent, his mother the daughter of an English Quaker. The family were not well off and William was apprenticed at an early age to Dr Phyle and then DrWilliam Smith. He also studied for two years at the University of Pennsylvania before entering practice in Abington in 1789, at the age of 21 . Four years later, with encouragement from Dr Benjamin Rush, he moved to Philadelphia where he took a special interest in midwifery. His thesis entitled "An Essay on the Means of Lessening Pain and Facilitating Certain Cases of Difficult Parturition" gained him a doctorate of medicine from the University of Pennsylvania in 1806. Meantime he had married Martha Rogers, daughter of $\mathrm{Dr}$ Rogers of New England. After her early death he married Mary Lorrain of Philadelphia in 1802.

Obstetrics having become his main clinical and teaching interest, Dewees applied without success for the newly founded chair in midwifery in 1810; the post went to $\mathrm{Dr}$ Thomas James. Shortly afterwards Dewees developed pulmonary tuberculosis and spent five years farming in Phillipsburgh before returning to his obstetric practice in Philadelphia in 1817. Meanwhile Dr James's health was failing and Dewees was made Adjunct Professor of Midwifery in 1825 and finally succeeded to the post of Professor of Obstetrics when Dr James retired in 1834. However, his tenure was short. The following year he had a stroke and was forced to resign. After four years in Mobile, Alabama, he returned to Philadelphia where he died at the age of 73 in $1841 .^{1}$

At the beginning of the 19th century childbirth in America was almost entirely in the hands of the midwives. Medical students were neither taught nor examined on the subject. Indeed, there was strong prejudice against men engaging in obstetrics. Dewees, however, appreciated its importance and was the first American doctor to attempt a full course of lectures on this subject and also on care of the newborn and the diseases of children. His text on midwifery, first published in 1824, were based to some extent on European authorities such as Baudelocque, and proved to be as popular as his lectures. It went through 12 editions. $^{2}$

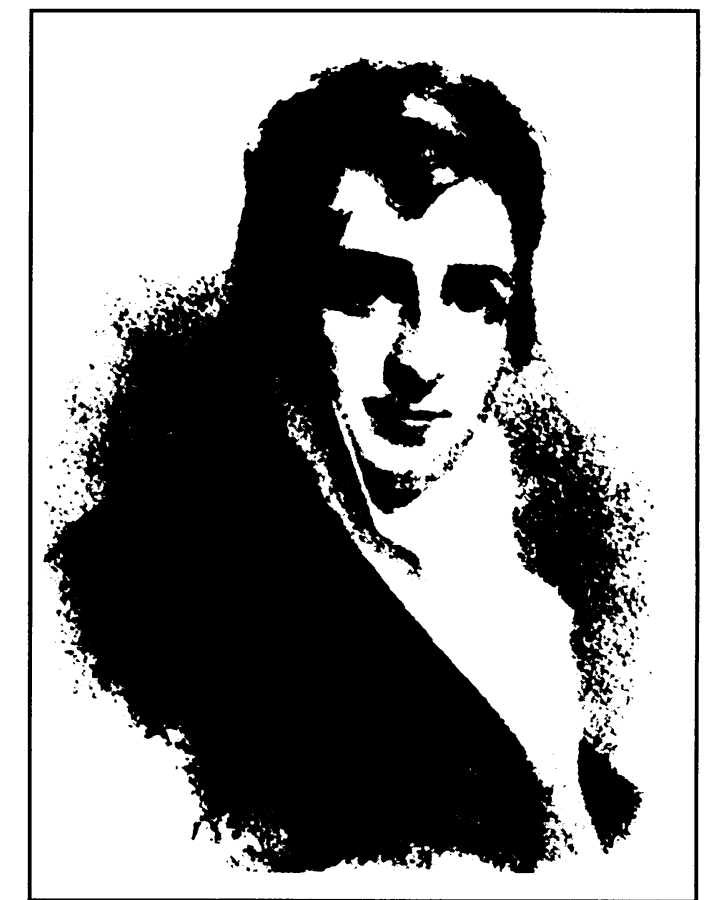

William Potts Dewees, 1768-1841.

Dewees' philosophy on childbirth, still relevant today, is reflected in the following extracts:

"I am very far from wishing to be understood, that I advocate the indiscriminate interference of art, during the progress of a healthy labour - it is the very reverse of my opinion, and of my practice; I wish merely to insist, that nature is not competent to all exigencies ... What has not that man to answer for, who shall permit a fellow creature to die, when a little address or knowledge might have saved her; or, what is perhaps still worse, who shall absolutely destroy her, by ill-judged, and rude manoeuvres, under the specious pretence of relieving her? Besides, the peculiar situation of our country, imposes a necessity upon every medical student, to become well acquainted with the theory of midwifery; for every one almost must practice it, if he pursue the object for which he is educated. A change of manners, within a few years, has resulted in the almost exclusive employment of the male practitioner... 
Ill-directed measures will always have penalties attached to them; and it is only by taking a proper view of the nature of the labour, that it can be conducted to a happy issue. There is no one circumstance, that so largely and certainly contributes to divert nature from her proper course, as the persuasion that art can always benefit her - hence, the constant employment of ill-directed manoeuvres by an ignorant accoucheur, or midwife. And unfortunately for the interest of humanity, it requires more knowledge not to be officious, than falls to the share of many of those, who pretend to practise midwifery... When all things are doing well, the active duties of the accoucheur, are limited indeed - it is but where the contrary obtain, that he can be said to be actively useful; but to discriminate between these two conditions, require a thorough knowledge of what a healthy labour consists..."

Dewees' thoughts on the management of the baby at birth and the delivery of the placenta are also relevant today:

\section{On management of the umbilical cord:}

"When respiration is established either spontaneously, or by artificial means (aspiration of mucus and mouth-to-mouth inflation), we apply a ligature to the cord, provided pulsation has ceased in it; but not until then ... The cord should be cut by a pair of scissors, half an inch at least beyond the ligature-it is never necessary to place two ligatures, except there be twins-indeed, it is best not to do so; as the evacuation from the open extremity of the cord will yield two or three ounces of blood sometimes, which favours the contraction of the uterus, and the expulsion of the placenta-it favours the contraction of the uterus, by the vessels of the placenta emptying themselves, and diminishing in bulk; this reduction proves a general and grateful stimulus to the uterus, and promotes its contraction; this contraction acts upon the placenta, so as to discharge it from its surface, that it may be expelled."

In 1825 Dewees published the first American textbook on paediatrics. ${ }^{3}$ It passed through nine editions; the first part dealt largely with care of the newborn and the second with the diseases of children. In the preface he states:

"The physical treatment of children should begin, as far as may be practicable, with the earliest formation of the embryo; it will, therefore, necessarily involve the conduct of the mother, even before her marriage, as well as during her pregnancy."

In his first chapter Dewees warns against the dangers of too early or premature marriage, or marriages of diseased persons or those likely to transmit hereditary diseases, and warns that: "in the woman too advanced (in years), the parts concerned in particular seem to have forgotten, in a degree, their offices; while in the too young female they have not entirely or perfectly acquired the capacity."

With respect to care of the newborn Dewees advised against swaddling and tight umbilical binders, advocating loose clothing to permit freedom of movement. Nappies should be changed frequently and babies prevented from becoming chilled, especially through bathing in cold water. His advice on infant feeding was also excellent:

\section{On breast feeding:}

"As the future health and welfare of the child, after birth, mainly depend on the healthfulness of the mother, and her capacity to supply it with sufficient and proper nourishment, it will follow; that this important office demands the utmost care, that she be enabled to perform this delightful duty with comfort to herself and advantage to her child ... She must not delegate, to any other being, the sacred and delightful task of suckling her child, unless there is the most decided and insurmountable impropriety in continuing it at her own breast ... Nourishment, and this derived, if possible, from the mother, is all that a newborn child requires..."

Where breast milk was inadequate, he recommended cow's milk, diluted with one third water to which a small quantity of sugar had been added, be given by bottle. He directed that the bottles be kept scrupulously clean, washed in hot water immediately after use, immersed in a soda solution while not in use, and rinsed in clear cold water before being used again. ${ }^{4} \mathrm{He}$ also recommended the "pasteurisation" of milk long before Pasteur.

Dewees is said to have been a very popular teacher and much beloved by his patients. He was undoubtedly a pioneer and founder of perinatal medicine in North America.

1 Ravdin IS. William Potts Dewees. Surg Gynecol Obstet 1936 62: 123-5.

Dewees WP A compendious system of midwifery. 2nd Edn. Philadelphia: Carey and Lea, 1826.

Dewees WP. A treatise on the physical and medical treatment of children. Philadelphia: Carey and Lea, 1825.

children. Philadelphia: Carey and Lea, 1825 . hundred years ago. Ann Med Hist 1936; 8: 36-43. 